\title{
A comparative evaluation of the effect of internet-based CME delivery format on satisfaction, knowledge and confidence
}

\author{
Vernon R Curran", Lisa J Fleet, Fran Kirby
}

\begin{abstract}
Background: Internet-based instruction in continuing medical education (CME) has been associated with favorable outcomes. However, more direct comparative studies of different Internet-based interventions, instructional methods, presentation formats, and approaches to implementation are needed. The purpose of this study was to conduct a comparative evaluation of two Internet-based CME delivery formats and the effect on satisfaction, knowledge and confidence outcomes.

Methods: Evaluative outcomes of two differing formats of an Internet-based CME course with identical subject matter were compared. A Scheduled Group Learning format involved case-based asynchronous discussions with peers and a facilitator over a scheduled 3-week delivery period. An eCME On Demand format did not include facilitated discussion and was not based on a schedule; participants could start and finish at any time. A retrospective, pre-post evaluation study design comparing identical satisfaction, knowledge and confidence outcome measures was conducted.

Results: Participants in the Scheduled Group Learning format reported significantly higher mean satisfaction ratings in some areas, performed significantly higher on a post-knowledge assessment and reported significantly higher post-confidence scores than participants in the eCME On Demand format that was not scheduled and did not include facilitated discussion activity.
\end{abstract}

Conclusions: The findings support the instructional benefits of a scheduled delivery format and facilitated asynchronous discussion in Internet-based CME.

\section{Background}

Larger numbers of physicians are using the Internet to locate and seek medical information and it has been suggested that one of its greatest benefits is as a tool for professional development [1-3]. Internet-based learning has become an increasingly popular approach to medical education [4-6] and Internet-based continuing medical education (CME) has grown steadily in the recent past $[7,8]$. The Internet has expanded opportunities for the provision of a flexible, convenient and interactive form of CME that has fulfilled the requirements of busy practitioners who have difficulty attending formal education sessions $[9,10]$.

\footnotetext{
* Correspondence: vcurran@mun.ca
Professional Development \& Conferencing Services, Faculty of Medicine,

* Correspondence: vcurran@mun.ca
Professional Development \& Conferencing Services, Faculty of Medicine, Memorial University, St John's, Canada
}

(c) 2010 Curran et al; licensee BioMed Central Ltd. This is an Open Access article distributed under the terms of the Creative Commons Attribution License (http://creativecommons.org/licenses/by/2.0), which permits unrestricted use, distribution, and reproduction in any medium, provided the original work is properly cited. able outcomes across a wide variety of learners, learning contexts, clinical topics and learning outcomes [5]. According to Wearne, [8] these programs can vary in style, content, relevance, reliability, authorship and sponsorship, and hence educational quality. A variety of Internet technologies, instructional methods and presentation formats are being used to provide both asynchronous and synchronous forms of Internet-based CME [2]. Internet-based CME is commonly offered, although not exclusively, through the use of learning management systems (LMS) and web conferencing systems. A learning management system is software for delivering, tracking and managing Internet-based education and often includes features for learning assessment and online collaboration (e.g. chat, discussion board and e-mail). Web conferencing systems can facilitate synchronous 
presentations via the Internet. Participants are connected with other participants through their computer and can view real-time presentations while interacting with a presenter over a standard telephone line or Voice over Internet Protocol (VoIP) audio technology. Some systems also include whiteboards, chat and polling features. In a systematic review of Internet-based CME literature, Cook et al.[5] found that Internet-based instruction addresses a wide range of topics with most interventions involving tutorials for self-study or virtual patients, and over a quarter requiring online discussion with peers, instructors or both.

The main benefits of Internet-based CME include: improved access, convenience and flexibility; reduced travel expenses and time; adaptability to learning styles; just-in-time learning; and an interactive multimedia format $[5,6,11,12]$. Curran and Fleet's [2] review of Internetbased CME evaluation literature found that physicians are generally satisfied with it and in some instances more satisfied than with traditional CME formats. Wutoh et al. [11] also reviewed the evaluation literature and concluded that Internet-based CME is as effective in imparting knowledge as traditional formats of CME. Cook et al.'s [5] systematic review found that Internet-based learning is educationally beneficial and can achieve results similar to those of traditional instructional methods. This review also suggested that effective learning outcomes appeared to be associated with cognitive interactivity, peer discussion, on-going access to instructional materials and practice exercises [5].

It has been suggested that further research comparing Internet-based interventions against no-intervention comparison groups is of little value [5]. Further research in the field should investigate elements of Internetbased CME that could make it more effective and efficient, such as specific instructional methods, presentation formats, and approaches to implementation [5]. According to Cook et al. [5] examining how to effectively implement Internet-based instruction must involve research directly comparing different Internet-based interventions. Curran and Fleet [2] have also suggested the need to examine in greater detail the nature and characteristics of those Internet-based learning technologies, environments and systems which are most effective. There are limited comparative studies of this nature reported in the Internet-based CME literature [2,5]. In one study, Beal et al. [13] compared the effectiveness of different curriculum delivery strategies (e.g., e-mail versus web site) and duration of delivery in providing Internet-based CME. They found no significant difference in knowledge, confidence and communication by curriculum delivery strategy.

A number of other studies have examined the specific use of both asynchronous technologies (e.g., e-mail, discussion boards) and synchronous technologies (e.g., Web conferencing) for facilitating Internet-based CME and the results have been generally mixed [2]. A number of authors report findings on the effectiveness of Internet-based CME facilitated by way of electronic mail or online discussion boards, however do not compare these approaches to other Internet-based interventions [14-17]. In one study, live CME participants made very little use of either e-mail or telephone to contact faculty, however $85 \%$ of online CME participants signed on at some point in time during web conferencing sessions [6]. Guan et al. [18] examined physicians' participation in online learning discussions, perceptions of online social closeness, and barriers and motivators to participation. Lack of time and peer response were given as the main reasons for low participation in learning discussions. Weir et al. [19] also studied the effectiveness of an e-mail based discussion forum using clinical cases as stimulus material. Message postings from 27 participants were most frequent during the first of four weeks and lowest during the second. Curran et al. [20] examined the nature of the interactions and collaborative learning characteristics exhibited in Internetbased CME that included asynchronous, text-based computer discussion. The results suggested that the nature of participation consisted primarily of independent messages with a minimal amount of learner-to-learner interaction [20].

While the literature examining the use of asynchronous communications (e.g. e-mail, discussion boards) in Internet-based CME is suggestive of some limitations in its use, the principles for supporting the use of such approaches is strongly supported by adult learning theory. One theory in particular, social constructivism, views learning to be an active rather than passive endeavor. Social constructivists propose that learning is a dialogic process in which communities of practitioners engage socially in talk and activity about shared problems or tasks $[21,22]$. Learning occurs through engaging, incorporating and critically exploring the views of others, while new possibilities of interpretations are opened through the interaction [21]. Making meaning is the ultimate goal of constructivist learning processes $[23,24]$, and to make meaning, constructivists believe that learners must be encouraged to articulate and reflect on what they know. Asynchronous communications are a critical component in the design of Internetbased constructivist learning environments (CLEs) as such technologies, if used effectively, can foster interaction, collaboration, and knowledge building. The communicative learning approaches which can be facilitated enable adult learners to participate in a collaborative process of building and reshaping understanding with and among their peers $[25,26]$. 
The purpose of the study described in this paper was to conduct a comparative evaluation of two differing Internet-based CME delivery strategies and the effect of a scheduled delivery format and facilitator-led asynchronous discussion instructional strategy on satisfaction, knowledge and confidence outcomes.

\section{Methods}

Two formats of an Internet-based CME course entitled Emergency Medicine (EM) (Trauma Cases) have been offered via the MDcme.ca web portal (Table 1). Both formats were developed using a proprietary Internetbased learning management system. The instructional design of the Scheduled Group Learning (SGL) format was based on participation in case-based asynchronous discussions with peers and a facilitator over a scheduled delivery period, and review of online learning tutorials and resources. The SGL format was offered over a three week period and participants were required to log-in and access the course at least twice over the scheduled duration and review discussion postings. The eCME On Demand instructional format was based mainly on principles of self-directed learning. This course format was not scheduled so participants could start and finish at any time. An asynchronous discussion board was available, however the discussion was not facilitated. Participants in the On Demand format were required to complete post-assessments to receive CME credit, however there was no requirement to post messages. Both formats were designed around case-based learning principles and learning objectives and subject matter was identical. Both formats were also offered free of charge and courses were promoted through the MDcme.ca web portal, web sites of other MDcme.ca consortium partners, the MDcme.ca newsletter distributed by e-mail messaging, and by promotion at professional conferences and meeting. The SGL format was offered 9 times

\section{Table 1 Internet-based CME Formats}

Format I: Scheduled Group Learning (SGL)

case-based, asynchronous discussions with peers and a facilitator (expert)

online learning tutorials and resources

offered over a scheduled delivery period

Format II: eCME On Demand

asynchronous discussion board available, however discussion was not facilitated

online learning tutorials and resources

self-directed learning design

not scheduled, participants could start at any time between February 2004 and October 2006, and On Demand was made available between June 2006 and September 2008.

Pre-to-post evaluation designs were applied to both course formats. Participants were self-selecting and restricted to licensed physicians (e.g., family medicine or specialists) and postgraduate residents. Participants in both formats were asked to complete an identical participant satisfaction survey, and pre-post knowledge and pre-post confidence assessment instruments. The satisfaction survey was comprised of 10 evaluative statements rated along a 5 -point Likert scale $(1=$ Strongly Disagree to $5=$ Strongly Agree). The survey was designed to evaluate several areas, including: content; design (navigability/process); and satisfaction with online discussions and interaction. Participants were also asked to complete pre and post-tests immediately prior to and after completion of a course, respectively. The pre and post-knowledge assessment was comprised of 5 identical one-best answer (A-type) MCQ items (1 key and 3 distractors), for a maximum score of 5 . The knowledge assessment was intended to measure participants' general knowledge of the subject matter covered in the courses. The pre and post-confidence assessment was comprised of 5 identical self-efficacy statements rated along a 5 -point Likert scale $(1=$ Strongly Disagree to 5 = Strongly Agree), for a maximum score of 25 . The confidence assessment was intended to measure participants' self-reported confidence in the clinical management of emergency trauma cases (e.g., I am confident in my ability to recognize the importance of complications in elderly patients with rib fractures; I am confident in my ability to discuss the approach to management of a dorsal dislocation of the PIP joint). The pre and postassessment instruments were available on-line using the quiz tool function of the learning management system.

Ethics approval was received from the Human Investigations Committee, Memorial University of Newfoundland.

\section{Results}

Table 2 summarizes the participant characteristics for both the SGL $(\mathrm{N}=29)$ and the On Demand $(\mathrm{N}=124)$ Internet-based CME formats. Groups were comparable across the majority of characteristics. The majority of participants in both formats were male $(69.0 \%$ SGL vs $54.0 \%$ On Demand), family physicians (60.7\% SGL vs 66.1\% On Demand) and reported experience of 10 years or less (51.7\% SGL vs 55.3\% On Demand). The majority of participants in both formats also reported practicing in communities with a population greater than 10,000 (75.0\% SGL vs $53.5 \%$ On Demand) and indicated computer skills to be of an intermediate level (69.0\% SGL vs 64.2\% On Demand). Pearson Chi Square analysis 
Table 2 Participant Characteristics

\begin{tabular}{|c|c|c|c|c|c|c|c|}
\hline \multicolumn{2}{|c|}{ Respondent Characteristics } & \multicolumn{2}{|c|}{ SGL } & \multicolumn{2}{|c|}{$\begin{array}{c}\text { On } \\
\text { Demand }\end{array}$} & \multicolumn{2}{|c|}{$\begin{array}{c}\text { Pearson } \\
\text { Chi } \\
\text { Square }\end{array}$} \\
\hline & & $\mathrm{N}$ & $\%$ & $\mathrm{~N}$ & $\%$ & df & Sig. \\
\hline \multirow[t]{2}{*}{ Gender } & Male & 20 & $69.0 \%$ & 67 & $54.0 \%$ & & \\
\hline & Female & 9 & $31.0 \%$ & 57 & $46.0 \%$ & 1 & .144 \\
\hline \multirow[t]{4}{*}{ Physician Type } & $\begin{array}{l}\text { Family } \\
\text { Physician }\end{array}$ & 17 & $60.7 \%$ & 82 & $66.1 \%$ & & \\
\hline & $\begin{array}{l}\text { Other } \\
\text { Specialist }\end{array}$ & 7 & $25.0 \%$ & 22 & $17.1 \%$ & 3 & .823 \\
\hline & Resident & 2 & $7.1 \%$ & 8 & $6.5 \%$ & & \\
\hline & Other & 2 & $7.1 \%$ & 12 & $9.7 \%$ & & \\
\hline Years of & $0-5$ years & 8 & $27.6 \%$ & 37 & $30.1 \%$ & & \\
\hline \multirow[t]{6}{*}{ Experience } & $6-10$ years & 7 & $24.1 \%$ & 31 & $25.2 \%$ & & \\
\hline & $11-15$ years & 8 & $27.6 \%$ & 20 & $16.3 \%$ & & \\
\hline & $16-20$ years & 1 & $3.4 \%$ & 10 & $8.1 \%$ & 6 & .558 \\
\hline & $21-25$ years & 2 & $6.9 \%$ & 18 & $14.6 \%$ & & \\
\hline & $26-30$ years & 2 & $6.9 \%$ & 6 & $4.9 \%$ & & \\
\hline & $>30$ years & 1 & $3.4 \%$ & 1 & $0.8 \%$ & & \\
\hline Size of Population & $<5,000$ & 4 & $14.3 \%$ & 33 & $27.0 \%$ & & \\
\hline That Depends on & $5,000-9,999$ & 3 & $10.7 \%$ & 24 & $19.7 \%$ & 2 & .111 \\
\hline $\begin{array}{l}\text { Participant for } \\
\text { Primary Care }\end{array}$ & $>10,000$ & 21 & $75.0 \%$ & 65 & $53.5 \%$ & & \\
\hline \multirow[t]{3}{*}{ Computer Skills } & Beginner & 3 & $10.3 \%$ & 11 & $8.9 \%$ & & \\
\hline & Intermediate & 20 & $69.0 \%$ & 79 & $64.2 \%$ & 2 & .788 \\
\hline & Expert & 6 & $20.7 \%$ & 33 & $26.8 \%$ & & \\
\hline Previous & Yes & 16 & $55.2 \%$ & 96 & $78.0 \%$ & 1 & .012 \\
\hline $\begin{array}{l}\text { Experience with } \\
\text { Online CME }\end{array}$ & No & 13 & $44.8 \%$ & 27 & $22.0 \%$ & & \\
\hline
\end{tabular}

indicated that the On Demand group had a significantly higher proportion of participants reporting previous online CME experience $(\mathrm{p}=.012)$.

Table 3 summarizes satisfaction ratings across the two formats. A total of 28 respondents from the SGL format completed the satisfaction survey while 124 from the eCME On Demand format responded. The ratings suggest respondents were very satisfied with the Internet-based instruction, regardless of format. Participants in both formats reported very positive overall mean scores for "The content was applicable to my practice" ( $M=4.57$ SGL vs $M=4.06$ On Demand) and "I would participate in another CME course offering of this type" ( $M=4.57 \mathrm{SGL}$ vs $M=4.34 \mathrm{On}$ Demand). An independent t-test analysis indicated that participants in the SGL format reported significantly higher mean ratings for items related to learning needs $(\mathrm{p}=.038)$ and clarity of content $(\mathrm{p}=.028)$ at the $\mathrm{p}<$ .05 probability level.
Table 4 summarizes the overall mean pre and postknowledge assessment scores. A total of 13 participants in the SGL format completed both pre and post-knowledge assessments while 74 participants from the On Demand format completed both assessments. Participants in the SGL format reported an overall mean preknowledge score of 2.38 and a post-knowledge score of 4.08. Participants in the On Demand format reported an overall mean pre-knowledge score of 1.72 and a postknowledge score of 3.08. A paired samples t-test analyses indicated a significant pre to post-knowledge increase $(\mathrm{p}=.000)$ for both course formats at the $\mathrm{p}<$ .05 probability level.

Table 5 summarizes the results of an independent samples $\mathrm{t}$-test comparing the pre and post-knowledge assessment results between formats. Participants in the SGL format performed significantly higher at the $\mathrm{p}<.05$ probability level on both the pre $(\mathrm{p}=.012)$ and postknowledge assessment $(p=.008)$ than participants in the On Demand format.

Table 6 summarizes the overall mean pre and postconfidence assessment scores. A total of 13 participants completed both the pre and post-confidence assessments in the SGL format while 73 participants completed both assessments in the On Demand format. Participants in the SGL format reported an overall mean pre-confidence score of 17.23 and a post-confidence score of 21.62. Participants in the On Demand format reported an overall mean pre-confidence score of 18.51 and a post-confidence score of 17.81. A paired samples $\mathrm{t}$-test analysis indicated that only participants in the SGL format reported a significant increase $(p=.005)$ in pre to post-confidence scores at the $\mathrm{p}<.05$ probability level.

Table 7 summarizes the results of an independent samples t-test comparing the pre and post-confidence assessment results between formats. Participants in the SGL format reported significantly higher post-confidence scores $(p=.039)$ than participants in the On Demand format at the $\mathrm{p}<.05$ probability level.

\section{Discussion}

The findings indicate that an Internet-based CME format involving facilitated asynchronous discussion activity and a delivery schedule over a three week time period resulted in more positive learning outcomes in comparison to an Internet-based CME format which was not based on a learning schedule and did not involve facilitated discussion activity. Participants in the SGL format reported significantly higher mean satisfaction ratings for items related to Internet-based CME "meeting learning needs" and "content being clear and easy to understand". Participants in this format also performed significantly higher on a post-knowledge 
Table 3 Satisfaction Ratings by Format*

\begin{tabular}{|c|c|c|c|c|c|}
\hline Survey Questions & Format & $\mathrm{N}$ & Mean Response & SD & Sig. \\
\hline The content addressed my learning needs. & $\begin{array}{c}\mathrm{SGL} \\
\text { On Demand }\end{array}$ & $\begin{array}{c}28 \\
122\end{array}$ & $\begin{array}{l}4.46 \\
3.94\end{array}$ & $\begin{array}{l}.576 \\
1.180\end{array}$ & .038 \\
\hline The content was applicable to my practice. & $\begin{array}{c}\text { SGL } \\
\text { On Demand }\end{array}$ & $\begin{array}{c}28 \\
122\end{array}$ & $\begin{array}{l}4.57 \\
4.06\end{array}$ & $\begin{array}{l}.504 \\
1.166\end{array}$ & .065 \\
\hline The content was clear and easy to understand. & $\begin{array}{c}\text { SGL } \\
\text { On Demand }\end{array}$ & $\begin{array}{c}28 \\
121\end{array}$ & $\begin{array}{l}4.61 \\
3.98\end{array}$ & $\begin{array}{c}.685 \\
1.235\end{array}$ & .028 \\
\hline This online course was easy to use. & $\begin{array}{c}\text { SGL } \\
\text { On Demand }\end{array}$ & $\begin{array}{c}28 \\
121\end{array}$ & $\begin{array}{l}4.14 \\
3.81\end{array}$ & $\begin{array}{l}1.044 \\
1.142\end{array}$ & .550 \\
\hline The pages were clearly laid out. & $\begin{array}{c}\text { SGL } \\
\text { On Demand }\end{array}$ & $\begin{array}{c}28 \\
119\end{array}$ & $\begin{array}{l}4.43 \\
4.10\end{array}$ & $\begin{array}{l}.690 \\
1.020\end{array}$ & .220 \\
\hline I received adequate help with technical problems. & $\begin{array}{c}\text { SGL } \\
\text { On Demand }\end{array}$ & $\begin{array}{l}14 \\
83\end{array}$ & $\begin{array}{l}3.29 \\
3.67\end{array}$ & $\begin{array}{l}.914 \\
1.083\end{array}$ & .209 \\
\hline Participating in the discussions enhanced my understanding of the content. & $\begin{array}{c}\text { SGL } \\
\text { On Demand }\end{array}$ & $\begin{array}{c}27 \\
107\end{array}$ & $\begin{array}{l}4.07 \\
3.89\end{array}$ & $\begin{array}{l}1.035 \\
.955\end{array}$ & .158 \\
\hline Being able to communicate with colleagues was helpful. & $\begin{array}{c}\text { SGL } \\
\text { On Demand }\end{array}$ & $\begin{array}{l}25 \\
91\end{array}$ & $\begin{array}{l}3.88 \\
3.56\end{array}$ & $\begin{array}{l}.927 \\
1.056\end{array}$ & .197 \\
\hline I would participate in another CME course offering of this type. & $\begin{array}{c}\text { SGL } \\
\text { On Demand }\end{array}$ & $\begin{array}{c}28 \\
117\end{array}$ & $\begin{array}{l}4.57 \\
4.34\end{array}$ & $\begin{array}{l}.790 \\
1.101\end{array}$ & .342 \\
\hline I would recommend this course to others. & $\begin{array}{c}\text { SGL } \\
\text { On Demand }\end{array}$ & $\begin{array}{c}28 \\
123\end{array}$ & $\begin{array}{l}4.57 \\
4.17\end{array}$ & $\begin{array}{l}.690 \\
1.092\end{array}$ & .063 \\
\hline
\end{tabular}

* Satisfaction survey was comprised of 10 evaluative statements rated along a 5 -point Likert scale $(1=$ Strongly Disagree to $5=$ Strongly Agree).

Table 4 Overall Pre to Post-Knowledge Change

\begin{tabular}{llcccc}
\hline Format & N & $\begin{array}{c}\text { Mean Score } \\
\text { (out of 5) }\end{array}$ & SD & Sig. \\
\hline SGL & Pre-CME & 13 & 2.38 & .768 & .000 \\
& Post-CME & 13 & 4.08 & 1.115 & \\
\multirow{2}{*}{ On Demand } & Pre-CME & 74 & 1.72 & .958 & .000 \\
& Post-CME & 74 & 3.08 & .962 & \\
\hline
\end{tabular}

Table 5 Pre to Post-Knowledge Change Between Formats

\begin{tabular}{llcccc}
\hline $\begin{array}{l}\text { Knowledge } \\
\text { Assessment }\end{array}$ & & $\mathrm{N}$ & $\begin{array}{c}\text { Mean Score } \\
\text { (out of 5) }\end{array}$ & SD & Sig. \\
\hline Pre-CME & SGL & 13 & 2.38 & .768 & .012 \\
& On Demand & 74 & 1.72 & .958 & \\
Post-CME & SGL & 13 & 4.08 & 1.115 & .008 \\
& On Demand & 74 & 3.08 & .962 & \\
\hline
\end{tabular}

assessment and reported significantly higher post-confidence scores than participants in the On Demand format. The higher level of online CME experience reported by participants in the On Demand format did not appear to affect learning outcomes of this group.

A primary limitation of this exploratory study is related to generalization. This was a study of the use of particular Internet-based learning technologies, delivery methods and learning approaches. As well, the subject matter of the courses was related to a very specific clinical area. The results must be viewed and interpreted in this context. The two course formats were offered at different time periods and it is possible that historical
Table 6 Overall Pre to Post-Confidence Change

\begin{tabular}{llcccc}
\hline Format & & N & $\begin{array}{c}\text { Mean Score } \\
\text { (out of 25) }\end{array}$ & SD & Sig. \\
\hline SGL & Pre-CME & 13 & 17.23 & 2.127 & .005 \\
& Post-CME & 13 & 21.62 & 5.378 & \\
\multirow{2}{*}{ On Demand } & Pre-CME & 73 & 18.51 & 4.634 & .505 \\
& Post-CME & 73 & 17.81 & 7.501 & \\
\hline
\end{tabular}

Table 7 Pre to Post-Confidence Change Between Formats

\begin{tabular}{llcccc}
\hline $\begin{array}{l}\text { Confidence } \\
\text { Assessment }\end{array}$ & & $\mathrm{N}$ & $\begin{array}{c}\text { Mean Score } \\
\text { (out of 25) }\end{array}$ & SD & Sig. \\
\hline Pre-CME & SGL & 13 & 17.23 & 2.127 & .120 \\
& On Demand & 73 & 18.51 & 4.634 & \\
Post-CME & SGL & 13 & 21.62 & 5.378 & .039 \\
& On Demand & 73 & 17.81 & 7.501 & \\
\hline
\end{tabular}

factors may have influenced the outcome measures and/ or participants' knowledge and attitudes may have changed during this time. Another limitation to the study was the difference in participant numbers between the two course formats. Registration for the SGL format was limited to 20 participants per course offering in order to foster enhanced facilitator interaction with participants. There was no limitation in registration for the On Demand course format. It is possible that the difference in the number of registrants between the course formats may have influenced the overall mean scores reported in the results. However, a comparison of participant characteristics did not indicate any significant differences 
between the study groups in terms of gender, physician type, years of experience, population size and computer skills. As well, a large number of participants did not complete both pre and post-knowledge and confidence assessments. The study results only represent matched scores for participants completing both pre and post assessments. Participants were not required to complete both pre and post assessment instruments to receive course credit.

Basing course completion around a schedule and supplementing instruction with a case-based asynchronous discussion board activity may have been key motivational factors in the SGL format and hence contributed to the positive learning outcomes. This finding is supported in previous research by Fordis et al. [6] who found that Internet-based CME participants often completed learning activities over several sessions. These researchers also reported that exposure to an educational activity (e.g., online discussion) combined with multi-session use of online materials may indicate an advantage of sequential reinforcement with Internetbased education [6]. It is likely that the increased interactivity and collaborative learning experiences afforded by an asynchronous discussion activity led by a facilitator, and subsequent opportunities for reflection on practice because of the scheduled nature of the learning, may have contributed to greater learning benefits.

The role of the facilitator in the SGL format was also not examined in detail and it is likely that the way in which the discussion board activities were facilitated may have influenced the learning outcomes for the participants in this format. Previous research does suggest that the level of asynchronous discussion participation by both facilitators and other participants in Internetbased CME is related to individual learner participation [27]. The findings of this study do highlight the significance of facilitated discussion and the important role of facilitation in fostering positive learning outcomes in Internet-based CME.

This study focused mainly on the effect of scheduled learning and asynchronous learning activities, however it is possible that synchronous instructional and communicative interaction facilitated through the use of real-time Web conferencing systems could also afford similar benefits. Future research should examine the comparative effectiveness and benefits of asynchronous versus synchronous interaction on similar learning outcome measures. A useful area for further research would also be to explore how "blended approaches" to Internet-based CME delivery, combining both asynchronous and synchronous formats, might be used effectively. It would also be beneficial for future studies to examine the effect of participation in differing Internet-based formats on subsequent physician practices and behavior. How can
Internet-based CME and associated technologies be used effectively to not only foster meaningful learning, but also support and foster knowledge transfer and practice change?

\section{Conclusions}

The purpose of this study was to conduct a comparative evaluation of two differing Internet-based CME delivery strategies and the effect of a scheduled delivery format and facilitator-led asynchronous discussion instructional strategy on satisfaction, knowledge and confidence outcomes. A Scheduled Group Learning (SGL) Internetbased CME format facilitated learning that incorporated participation in case-based asynchronous discussions with peers and a facilitator over a scheduled delivery period. An eCME On Demand Internet-based CME format was not scheduled so participants could start and finish at any time. The results of the study indicate that the SGL format resulted in more positive learning outcomes in comparison to the On Demand format. Participants in the SGL format reported significantly higher mean satisfaction ratings, performed significantly higher on a post-knowledge assessment and reported significantly higher post-confidence scores. The findings from this study support the instructional benefits of a scheduled delivery format and facilitated asynchronous discussion in the delivery of Internet-based CME.

\section{Acknowledgements}

Development of the content for EM (Trauma Cases) was funded by the Atlantic Canada Opportunities Agency (ACOA), Atlantic Innovation Fund. ACOA also supported delivery of this content in the SGL format. The content was re-formatted for On Demand delivery by the Online Development Team of Professional Development \& Conferencing Services (PDCS), Faculty of Medicine, Memorial University and supported by the MDcme Consortium.

\section{Authors' contributions}

VC led the conceptualization of the study design, participated in data analysis and led the preparation of the manuscript. LF led data collection and analysis, and participated in drafting the manuscript. FK helped to draft the manuscript. All authors read and approved the final manuscript.

\section{Competing interests}

The authors declare that they have no competing interests.

Received: 20 July 2009

Accepted: 29 January 2010 Published: 29 January 2010

\section{References}

1. Bennett NL, Casebeer LL, Kristofco R, Collins BC: Family physicians' information seeking behaviors: a survey comparison with other specialties. BMC Medical Informatics and Decision Making 2005, 5:9.

2. Curran V, Fleet $L$ : A review of evaluation outcomes of web-based continuing medical education. Medical Education 2005, 39:561-67.

3. Casebeer L, Bennett N, Kristofco R, Carillo A, Centor R: Physician internet medical information seeking and on-line continuing education use patterns. Journal of Continuing Education in the Health Professions 2002, 22(1):33-42

4. Bergeron B: Online CME options: an update. Journal of Medical Practice Management 2006, 22(1):55-7. 
5. Cook DA, Levinson AJ, Garside S, Dupras DM, Erwin PJ, Montori VM: Internet based learning in the health professions. Journal of the American Medical Association 2008, 300(10):1181-1196.

6. Fordis M, King J, Ballantyne C, Jones P, Schneider K, Spann S, Greenberg SB, Greisinger AJ: Comparison of the instructional efficacy of Internet-based CME with live interactive CME workshops: a randomized controlled trial. Journal of the American Medical Association 2005, 294(9):1043-1051.

7. Olson CA, Shershneva MB: Setting quality standards for web-based continuing medical education. Journal of Continuing Education in the Health Professions 2004, 24(2):100-11.

8. Wearne S: Trapped in the net? What to look for in a web based CPD program. Australian Family Physician 2008, 37(10):845-8.

9. Casebeer LL, Strasser SM, Spettell CM, Wall TC, Weissman N, Ray MN, Allison JJ: Designing tailored Web-based instruction to improve practicing physicians' preventive practices. Journal of Medical Internet Research 2003, 5(3):e20.

10. Sly JL, Lombardi E, Kusel M, Sly PD: Piloting a web-based continuing professional development program for asthma education. International Journal of Medical Informatics 2006, 75(10-11):708-13.

11. Wutoh R, Boren SA, Balas A: eLearning: a review of Internet-based continuing medical education. Journal of Continuing Education in the Health Professions 2004, 24(1):20-30.

12. Zeiger RF: Toward continuous medical education. Journal of General Internal Medicine 2005, 20(1):91-4.

13. Beal T, Kemper KJ, Gardiner P, Woods C: Long-term impact of four different strategies for delivering an on-line curriculum about herbs and other dietary supplements. BMC Medical Education 2006, 6:39.

14. Ryan D, Waterson R: Transforming continuing education materials for online learning. Journal of Telemedicine and Telecare 2000, 6(4 Suppl 2):64-66.

15. Marshall JN, Stewart M, Ostbye T: Small-group CME using email discussions: can it work?. Canadian Family Physician 2001, 47:557-563.

16. Chan DH, Leclair K, Kaczorowski J: Problem-based small-group learning via the Internet among community family physicians: a randomized controlled trial. MD Computing: Computers in Medical Practice 1999, 16(3):54-58.

17. Sargeant JM, Purdy RA, Allen MJ, Nadkami S, Watton L, O'Brien P: Evaluation of a CME problem-based learning discussion. Academic Medicine 2000, 75(10 Suppl):S50-S52.

18. Guan J, Tregonning S, Keenan L: Social interaction and participation: formative evaluation of online CME modules. Journal of Continuing Education in the Health Professions 2008, 28(3):172-9.

19. Weir E, Stieb DM, Abelsohn A, Mak M, Kosatsky T: Design, delivery and evaluation of an email-based continuing professional development course on outdoor air pollution and health. Medical Teacher 2004, 26(2):166-73.

20. Curran V, Kirby F, Parsons E, Lockyer J: Discourse analysis of computermediated conferencing in World Wide Web-based continuing medical education. Journal of Continuing Education in the Health Professions 2003, 23(4):229-38

21. Merriam SB, Caffarella RS, Baumgartner LM: Learning in adulthood: a comprehensive guide San Francisco (CA): Jossey-Bass, 32007.

22. Jonassen DH, Myers JM, McKillop AM: From constructivism to constructionism: learning with hypermedia/multimedia rather than from it. Constructivist learning environments Englewood Cliffs (NJ): Educational Technology PublicationsWilson BG 1996, 93-106.

23. Reeves TC, Oakley JR: Alternative assessment for constructivist learning environments. Constructivist learning environments Englewood Cliffs ( $\mathrm{NJ}$ ), Educational Technology PublicationsWilson BG 1996, 191-202.

24. Graham M, Scarborough H: Computer mediated communication and collaborative learning in an undergraduate distance education environment. Australian Journal of Educational Technology 1999 15(1):20-46.

25. Jonassen D, Davidson M, Collins M, Campbell J, Haag BB: Constructivism and computer-mediated communication in distance education. American Journal of Distance Education 1995, 9(2):7-26.

26. McAlpine I: Collaborative learning on-line. Distance Education 2000, 21(1):66-80

27. Curran VR, Lockyer J, Kirby F, Sargeant J, Fleet L, Wright D: The Nature of the Interaction between Participants and Facilitators in On-line Asynchronous Continuing Medical Education Learning Environments. Teaching and Learning in Medicine 2005, 17(3):240-246.

\section{Pre-publication history}

The pre-publication history for this paper can be accessed here:http://www. biomedcentral.com/1472-6920/10/10/prepub

doi:10.1186/1472-6920-10-10

Cite this article as: Curran et al:: A comparative evaluation of the effect of internet-based CME delivery format on satisfaction, knowledge and confidence. BMC Medical Education 2010 10:10.

\section{Submit your next manuscript to BioMed Central and take full advantage of:}

- Convenient online submission

- Thorough peer review

- No space constraints or color figure charges

- Immediate publication on acceptance

- Inclusion in PubMed, CAS, Scopus and Google Scholar

- Research which is freely available for redistribution

Submit your manuscript at www.biomedcentral.com/submit
C Biomed Central 